\section{Hospital Based Nutrition Support: A Review of the Latest Evidence}

\section{Abstract}

Meeting appropriate nutritional demands in the inpatient setting is a fundamental aspect of optimal patient care. Optimizing nutrition delivery and preventing malnutrition can have a significant positive effect on clinical outcomes and costs of care. Despite extensive research, many questions remain regarding the delivery of nutrients to hospitalized patients, especially in the critically ill. Recent advances have been made over the past decade, and landmark studies have yielded an end to many controversial topics, such as the broad utilization of immunonutrition. However, there are still many questions that remain unanswered, for example how do we objectively define malnutrition? Cutting edge research in the areas of morphomics and metabolomics are raising new questions which are poised to revolutionize how we will answer today's questions. In this review, we summarize the historical pedagogy underlying nutritional practice alongside contemporary evidence supporting current practice guidelines. Furthermore, we identify and explore key barriers preventing the rapid identification and treatment of malnutrition. We introduce two emerging technologies foremost in nutritional research that may eventually disrupt current barriers. And finally, we discuss key populations at specifically high risk for the development of malnutrition.

Keywords: Hospitalized patients; Nutrition support; Malnutrition; Wound healing

\section{Christopher J. Tignanelli ${ }^{*}$ and Jill Cherry - Bukowiec ${ }^{2}$}

\author{
1 Department of Surgery, University of \\ Minnesota, Minneapolis, MN, USA \\ 2 Department of Surgery, University of \\ Michigan, Ann Arbor, MI, USA
}

\section{*Corresponding author: \\ Christopher J. Tignanelli}

\section{झ ctignane@umn.edu}

Department of Surgery, University of Minnesota, 420 Delaware St SE, MMC 195, Minneapolis, USA.

Tel: (612) 626-1968

Fax: (612) 626-0439

Citation: Tignanelli CJ, Bukowiec JC (2017) Hospital Based Nutrition Support: A Review of the Latest Evidence. J Clin Nutr Diet Vol. 3 No. 3:22.

Received: September 08, 2017; Accepted: September 25, 2017; Published: September 30, 2017

\section{Introduction}

The importance of appropriate nutritional therapy in hospitalized patients was brought to light in a 1974 publication by Charles Butterworth "The skeleton in the hospital closet". In this article, he encouraged increased physician attention to what he termed as "iatrogenic malnutrition" [1]. Despite four decades since this publication, appropriate attention to nutritional management remains lacking. For example, a 2001 study of Medicare patients at risk for pressure ulcers showed that $76 \%$ were malnourished, and only $34 \%$ of patients at risk for pressure ulcers received nutritional consultation [2]. This neglect for the appropriate delivery of nutritional care stems beyond just the inpatient setting, but also to medical and graduate medical education where nutrition is underrepresented in training programs $[3,4]$.

The appropriate nutrition of hospitalized patients has a direct effect on patient outcomes. Creating systems aimed at identifying patients at significant nutritional risk and monitoring adherence to evidenced based nutritional care practices have the potential to significantly improve outcomes and reduce costs. Patients who develop malnutrition represent a missed opportunity to deliver the critical nutrients needed and prevent the ramifications that come with a malnourished state. Despite increased calls for better nutritional screening, 1 in 3 patients who present to a hospital already meet the criteria for malnutrition [5]. Malnutrition has significant clinical and economic ramifications. For example, surgical patients, who are just at risk for malnutrition, have a twofold increased risk of post-operative complications, significantly longer length of stay (LOS), increased mortality, and higher costs. 6 A 2013 review on malnutrition demonstrated hospital malnutrition is associated with an increased rate of pressure ulcers, impaired wound healing, infection rates (Clostridium difficile, surgical site infections (SSI), pneumonia, mediastinitis, catheter associated urinary tract infection (CAUTI)), risk of falls, increased LOS, readmission rates, costs, and mortality [58]. However malnutrition is preventable and treatable, with multiple meta-analyses demonstrating that optimal delivery of appropriate nutrition is associated with significantly reduced mortality $[9,10]$. This review summarizes key barriers preventing the early recognition and treatment of malnourished patients and the controversies and practice guidelines surrounding current clinical practice. 


\section{Defining Malnutrition}

Malnutrition is a major public health issue associated with substantial medical and economic implications. Hospitalized patients are at significant risk for malnutrition, with an estimated at risk prevalence ranging between 13-78\% [11] Unfortunately, great controversy surrounds the formal definition of malnutrition, with multiple societies proposing contrasting definitions. Furthermore, this lack of a consistent objective measure for malnutrition leads to bias in diagnosis putting many patients at risk for misdiagnosis. This lack of an objective definition is likely because many nutritional parameters may be a mere reflection of the severity of patient illness rather than of nutritional status. This also severely limits the direct comparison of nutritional studies. A formal definition provided by a joint consensus statement from the Academy of Nutrition and Dietetics and American Society for Parenteral and Enteral Nutrition (ASPEN) recommends at least 2 of the following 6 characteristics for a diagnosis of malnutrition: weight loss, insufficient energy intake, muscle or fat loss, fluid accumulation, and diminished functional status as measured by hand grip strength [12]. As previously stated the subjective nature of this definition leaves many patients at risk for malnutrition which is often underdiagnosed and undertreated. Many have attempted to define malnutrition in terms of objectives measures such as weight, body mass index (BMI), mid arm circumference, albumin, prealbumin, retinol binding protein, and total lymphocyte count. Unfortunately, these measures alone are not optimal, and are impacted by fluid shifts, inflammation, and many other factors not directly related to nutrition status. There remains a current need for an evidenced based and objective definition for malnutrition.

While an objective definition is lacking, the risk factors for malnutrition are better defined. Malnutrition suffers from two sets of risk factors. Patient-specific risk factors include age and poor functional status, specific disease processes (cancer, alcoholism, gastrointestinal disease, and surgery), and treatments such as mechanical ventilation [11]. In contrast, organizational factors are a major and preventable source of malnutrition risk. These factors include: failure to recognize malnutrition, lack of nutritional screening, lack of training, confusion regarding responsibility, and failure to record height and weight. Patientspecific risk factors are less likely to be modifiable, as the majority are present on admission or due to severity of disease; however, organizational risk factors are potentially high yield targets for nutritional intervention. Quality improvement efforts should focus on reducing institutional barriers enabling the under diagnosis and under treatment of malnutrition.

\section{Indicators of Nutritional Status}

While it is important to be aware of the risk factors for malnutrition, the ability to objectively assess a patients' nutritional state is perhaps even more important. Historically, this has been done through the measurement of albumin, with hypoalbuminemia defined as lower than $3.5 \mathrm{~g} / \mathrm{dL}$. However, as we previously mentioned this and other "objective" measures of malnutrition have significant clinical flaws. Despite these flaws, pre-operative albumin evaluation is so ubiquitous that it is routinely ordered prior to $75 \%$ of all elective operations, and has been shown to be one of the strongest pre-operative predictors of post-operative morbidity [13]. However, albumin alone is a poor marker of nutritional status for hospitalized patients. Volume status, renal and liver disease, and enteropathies are just a few of the disease processes which can alter albumin levels. Another limitation of albumin is its long half-life (20 days), diminishing it's reliably to assess short-term nutritional changes. Another indicator routinely ordered is prealbumin. One key advantage of prealbumin is that its half-life is only 2 days, allowing for short-term trends of patients' nutritional status (Table 1). Some evidence suggests that improving prealbumin levels may be a prognostic marker for certain subsets of patients (i.e., traumatic brain injury and renal injury); however, caution is recommended if using prealbumin to guide nutritional therapy as many disease processes affect levels (i.e., steroid use, alcoholism, inflammatory state, and micronutrient deficiencies) $[14,15]$ Unfortunately, in critically ill patients, where objective markers of nutritional status are needed most, prealbumin suffers from its role as an acute phase reactant, and thus is affected by many of the same disease states that affect albumin levels. Furthermore, renal disease has been shown to increase prealbumin levels acutely. While these values can serve as potential markers of nutritional status, it's important to point out that no studies have shown correcting these values results in improved outcomes in critically ill patients. Routine monitoring of acute phase reactants and attempts to correct abnormalities is thus not recommended [16,17].

C-reactive protein (CRP) is another acute phase reactant that is theorized to help gauge nutritional status (Table 1). Given the inflammatory states' effect on the utilization of prealbumin and albumin for nutritional assessment, the addition of CRP measurement has been suggested to differentiate inflammatory states with malnutrition states. Normally, CRP levels are inversely correlated with prealbumin levels in patients with inflammation [18]. However, in patients with weight loss and malnutrition, CRP and albumin both remain low [19] While data is limited, one study evaluated the routine utilization of CRP, albumin, and prealbumin in burn patients, and recommended the following framework. In patients with low albumin, prealbumin, and high CRP they argue inflammation is the likely culprit, in patients where all three remain low, malnutrition is the likely culprit [20]. This method likely oversimplifies the problem as these acute phase markers peak at various time periods during the inflammatory response limiting their usefulness clinically. A recent study evaluating the relationship of prealbumin and CRP in critically ill patients receiving enteral feeds noted no differences in prealbumin levels for patients being underfed or adequately fed and noted that inflammation seemed to be the main driver of rising prealbumin levels in the critically ill [16]. Transferrin is another acute phase reactant with an intermediate half-life compared with albumin and prealbumin. Unfortunately, this marker is also privy to fluctuations related to a multitude of other factors and its routine assessment is not recommended.

Another indicator of nutritional status that is less frequently utilized in the present day is nitrogen balance. Nitrogen balance is a measure of the gain or loss of protein (Table 1). Within $4 \mathrm{~g} /$ day is considered equilibrium. To best understand the limitations of 
Table 1 Chemical and anthropometric indicators of nutritional status.

\begin{tabular}{|c|c|c|c|}
\hline Parameter & Normal & At risk for malnutrition & Half-life \\
\hline \multirow{3}{*}{ Albumin } & \multirow{3}{*}{$3.5-5.0 \mathrm{~g} / \mathrm{dL}$} & Mild: $3.0-3.4 \mathrm{~g} / \mathrm{dL}$ & \multirow{3}{*}{20 days } \\
\hline & & Moderate: $2.4-2.9 \mathrm{~g} / \mathrm{dL}$ & \\
\hline & & Severe: $<2.4 \mathrm{~g} / \mathrm{dL}$ & \\
\hline \multirow{3}{*}{ Prealbumin } & \multirow{3}{*}{$16-40 \mathrm{mg} / \mathrm{dL}$} & Mild: $10-15 \mathrm{mg} / \mathrm{dL}$ & \multirow{3}{*}{2 days } \\
\hline & & Moderate: $5-9 \mathrm{mg} / \mathrm{dL}$ & \\
\hline & & Severe: $<5 \mathrm{mg} / \mathrm{dL}$ & \\
\hline$C$ reactive protein (CRP) & $<0.8 \mathrm{mg} / \mathrm{dL}$ & & 19 hours \\
\hline \multirow{3}{*}{ Transferrin } & \multirow{3}{*}{$200-400 \mathrm{mg} / \mathrm{dL}$} & Mild: $150-200 \mathrm{mg} / \mathrm{dL}$ & \multirow{3}{*}{9 days } \\
\hline & & Moderate: $100-149$ mg/dL & \\
\hline & & Severe: $<100 \mathrm{mg} / \mathrm{dL}$ & \\
\hline Nitrogen Balance & \pm 4 grams/day & & \\
\hline \multirow{2}{*}{ Triceps skin fold thickness (1) } & Male: $11-12.5 \mathrm{~mm}$ & $<6.1 \mathrm{~mm}$ & \\
\hline & Female: $15-16.5$ mm & $<11.6 \mathrm{~mm}$ & \\
\hline \multirow{2}{*}{ Body mass index (BMI) } & \multirow{2}{*}{$18.5-24.9$} & At risk if $<18.5$ & \\
\hline & & or $>24.9$ & \\
\hline Calf circumference (2) & $31-33 \mathrm{~cm}$ & $<31 \mathrm{~cm}$ & \\
\hline \multirow{2}{*}{$\begin{array}{l}\text { Mid upper arm circumference (MUAC) } \\
\text { (3) }\end{array}$} & Male: $25-29$ & $<24.7 \mathrm{~cm}$ & \\
\hline & Female: $23.5-28.5 \mathrm{~cm}$ & $<23.5 \mathrm{~cm}$ & \\
\hline \multirow{2}{*}{$\begin{array}{l}\text { Waist to hip circumference ratio (WHR) } \\
\text { (3) }\end{array}$} & Male: $<0.90$ & Male: $>0.90$ & \\
\hline & Female: $<0.85$ & Female: $>0.85$ & \\
\hline \multirow{2}{*}{$\begin{array}{l}\text { Mid arm muscle circumference (MMC) } \\
\text { (4) }\end{array}$} & Male: $23-25 \mathrm{~cm}$ & $<21.1 \mathrm{~cm}$ & \\
\hline & Female: $20-23 \mathrm{~cm}$ & $<19.2 \mathrm{~cm}$ & \\
\hline
\end{tabular}

1. McDowell MA, Fryar CD, Ogden CL, Flegal KM. Anthropometric reference data for children and adults: United States, 2003-2006. Natl Health Stat Report. 2008(10):1-48.

2. Rolland $\mathrm{Y}$, Lauwers-Cances $\mathrm{V}$, Cournot $\mathrm{M}$, et al. Sarcopenia, calf circumference, and physical function of elderly women: a cross-sectional study. J Am Geriatr Soc. 2003;51(8):1120-1124.

3. Madden AM, Smith S. Body composition and morphological assessment of nutritional status in adults: a review of anthropometric variables. J Hum Nutr Diet. 2016;29(1):7-25.

4. Landi F, Russo A, Liperoti R, et al. Midarm muscle circumference, physical performance and mortality: results from the aging and longevity study in the Sirente geographic area (ilSIRENTE study). Clin Nutr. 2010;29(4):441-447.

this method one must understand how it is calculated. Nitrogen balance measures the excreted BUN and adds a constant of $4 \mathrm{~g} /$ day to that value. This constant estimate is derived from estimated non urinary urea nitrogen and gastrointestinal losses. There are significant limitations and confounding factors which can greatly skew the accuracy of this method (i.e., diarrhea). Furthermore, no large randomized trials evaluating the use of nitrogen balance to guide protein supplementation have shown a correlation with clinical outcomes [21]. Given this, the routine measurement of nitrogen balance has fallen out of favor and is no longer recommended.

Multiple anthropometric parameters exist to gauge nutritional status. Triceps skin fold thickness, BMI, calf circumference, mid upper arm circumference, waist to hip ratio, and mid arm muscle circumference have all been recommended (Table 1). Multiple studies have evaluated these parameters and how well they correlate with nutritional status. In one cross-sectional study of 109 elderly patients, arm circumference was the best predictor of nutritional status, this was followed by $\mathrm{BMI}$, triceps skin fold thickness, and finally mid-arm circumference [22]. However, these methods are not utilized frequently to assess nutritional status, outside of BMI, for hospitalized patients as they all suffer from severe limitations. Many of these techniques suffer from lack of reliability. For example, studies have identified that arm circumference suffers from significant inter-observer variation depending where measurements are taken and how taut the measuring tape is pulled [23]. Another well-known limitation of BMI is its inability to account for a patient's muscular state. Thus while many objective markers of nutritional status and thus malnutrition have been proposed, they are not without issues. The holy grail for objective measures of nutritional status continues and we recommend against the routine use of the above elements as independent measures of nutritional status and degree of malnutrition.

\section{Screening for Nutritional Risk and Assessment of Malnutrition Using Scoring Systems}

With a single objective measure for malnutrition lacking, there has been much enthusiasm using nutritional scoring systems to either screen for nutritional risk or assess a patient's degree of malnutrition. Scoring systems have the benefit of aggregating multiple nutritional indicators to better screen nutritional risk and assess the degree of malnutrition. A few examples of scoring systems used to screen for nutritional risk include: Nutritional risk screening (NRS 2002), Malnutrition screening tool (MST), Malnutrition universal screening tool (MUST), and 
the NUTRIC score. Other systems such as, the Subjective Global Assessment (SGA) categorize the degree (i.e., moderate, severe) of malnutrition present [6]. These scoring systems allow for the rapid identification of patients at significant nutritional risk or the categorization of the degree of malnutrition permitting more aggressive efforts to improve nutritional status and combat malnutrition.

The two screening systems most frequently utilized in the inpatient setting include the NRS 2002 and the NUTRIC score (Table 2). The NRS 2002 was developed to identify patients who are most likely to benefit from nutritional support [24]. It was validated retrospectively against data from 128 clinical trials and showed that patients who fulfilled the criteria were more likely to have a positive clinical outcome with nutritional support than patients who did not meet these criteria. This method has also been evaluated prospectively in 212 patients. Those with an NRS 2002 greater than two received nutritional intervention resulting in an increase in net calories, reduction in the severity of complications, reduced LOS for patients with complications, and reduced LOS related to nutritional support [25].

The NUTRIC score is the most frequently utilized scoring system in the critical care setting. It was developed from 597 ICU admissions (excluding elective surgery and overdoses) (Table 2) [26]. One advantage of this system over the NRS 2002 is that it also takes into account disease severity by utilizing the patient's APACHE II and sequential organ failure assessment (SOFA) scores. This scoring system correlates well with mortality and duration of mechanical ventilation. More importantly, in patients with a high nutritional risk, defined as NUTRIC score greater than five, mortality is directly correlated with the percent of calories received. Patient's receiving near $100 \%$ of caloric needs had the lowest mortality compared with underfed patients. Without an objective gauge for malnutrition it is our practice to routinely utilize the NUTRIC score to gauge nutritional risk in our critical ill patients.

\section{Analytic morphomics}

Advances in analytic morphomics and metabolomics offer novel insights into the identification of the malnourished patient. Promising studies involving analytic morphomics allow the quantification of body tissue composition from images such as computerized tomography (CT) scans, thus allowing for a quantitative measure of sarcopenia and malnutrition. Given the limitations of objective measures of nutritional status the development of this technology is welcomed. One area where this technology has already proven beneficial is in the routine preoperative risk assessment preceding elective surgery. A common parameter used in analytic morphomics is the total psoas area (TPA) measured at the L4 vertebral landmark. This measure is then compared with gender specific norms as a surrogate marker for sarcopenia $[27,28]$. In one study specifically evaluating TPA in the elderly, increased TPA was shown to be inversely proportional with impaired mobility in elderly patients and directly proportional with reduced cognitive impairment and ability to perform activities of daily living [29]. Furthermore, morphomics elements such as TPA, have been shown to be independent predictors for morbidity and mortality in patients undergoing many types of surgeries, including liver transplantation, colectomies for cancer, and bowel resection for Crohn's disease [30-32].

\section{Metabolomics}

Another cutting edge field of nutrition research involves metabolomics, or the study of a patient's individual metabolic profile determined from blood, urine, and stool samples. While this technology has not yet been used clinically in the inpatient arena, it is important for the reader to be aware of its presence in the outpatient setting. Current research in this field analyzes patient's biochemical pathways to identify changes in response to dietary patterns and disease processes. Another goal of this field seeks to identify nutritional biomarkers which can be used to later guide comparative nutritional research [33]. In one study researchers identified that low leptin levels were a prognostic biomarker for mortality in patients with severe acute

Table 2 Comparison of NRS 2002 and NUTRIC nutritional risk screening systems.

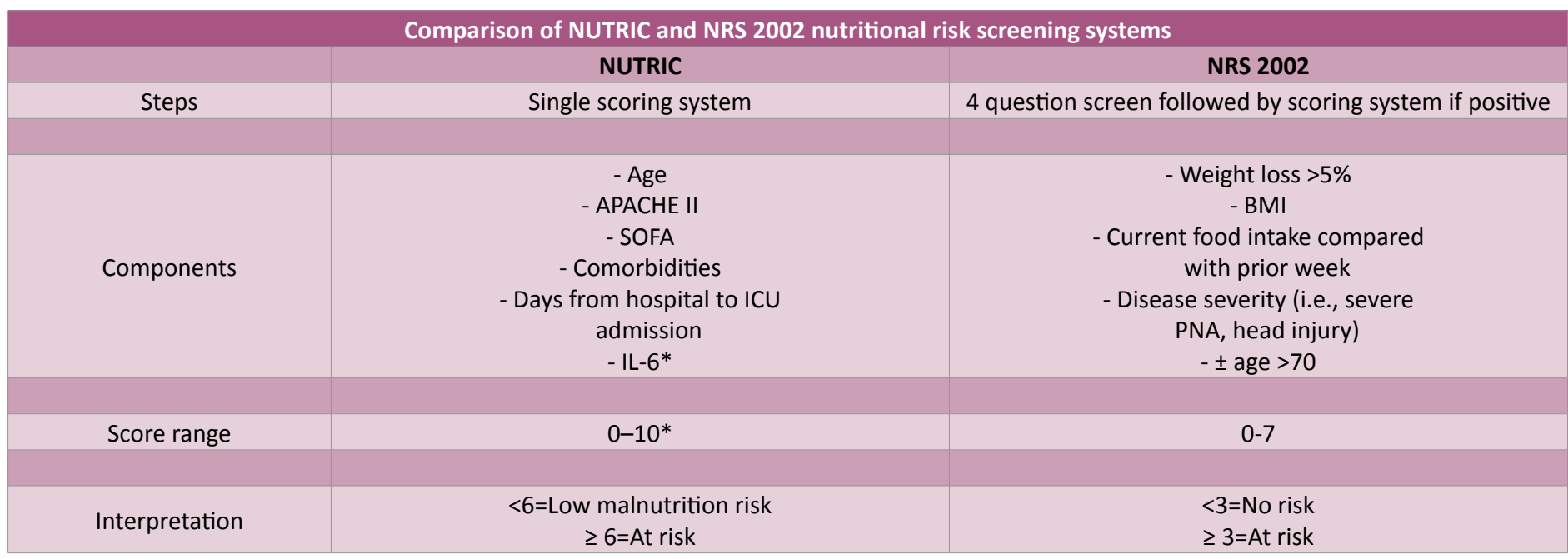

SOFA, sequential organ failure assessment; BMI, body mass index; PNA, pneumonia

* Many don't include IL-6. If unavailable: score range $0-9$, and $\geq 5=$ at risk for malnutrition 
malnutrition [34]. Eventually, the definition of malnutrition may include metabolomic and morphomic elements; however, these fields are still in their infancy. Until then clinicians must rely on scoring systems and subjective criteria currently available.

\section{Methods to calculate nutritional needs}

Even if one could identify every patient at risk for, or with malnutrition, controversy exists over the optimal number of calories patients should receive. To deliver the appropriate amount of nutrition for hospitalized patients one must be able to determine caloric requirements. For many patients, equations can adequately estimate energy expenditure. However, predictive equation estimates tend to be inaccurate in critically ill patient populations [35]. This leaves the majority of critically ill patients at significant risk for under and over feeding. One population of critically ill patients can benefit from the routine utilization of indirect calorimetry (IC). This technique allows for the direct measurement of resting energy expenditure in patients requiring mechanical ventilation. In this method, oxygen consumption and carbon dioxide production are measured to calculate energy expenditure. Though considered the gold standard, IC is not available in many ICU's as it requires expensive equipment and highly trained personnel. Additionally, randomized data is limited regarding the role of IC and clinical outcomes. The TICACOS trial, a single center pilot study of 130 mechanically ventilated patients, identified a trend towards reduced mortality in patient whose nutritional requirements were determined by IC ( $32.3 \%$ vs. $47.7 \%, p=0.058$ ), despite significantly longer ventilator and ICU LOS.36 Given the lack of definitive benefit and the high resource utilization required for IC, many practitioners resort to estimating energy requirements using specific caloric goals, such as the Harris-Benedict equation (HBE). While a detailed review of each of these methods is outside the scope of this paper, commonly used equations are a specific calorie goal of 25-30 calories/kg/ day, the HBE, or in critically ill patients the Ireton-Jones equation. If predictive equations are being used to estimate a patient's energy expenditure, it is important to add a $10-50 \%$ stress factor accounting for the increased metabolic demands of the patient's disease state. Despite this, we and others have shown that these equations are wildly inaccurate putting patients at significant risks for over and under feeding [36]. We recommend the routine utilization of IC in mechanically ventilated critically ill patients. In patients who cannot receive IC, we resort to specific calorie goal calculations to determine nutritional needs with frequent re-assessments.

\section{Methods to deliver nutrition and considerations}

The optimal route of feeding is less controversial, in patients who can safely tolerate per os (PO) this is always the preferred route. In patients who cannot tolerate $\mathrm{PO}$ due to mechanical ventilation, aspiration, or other disease states, nasogastric or nasoduodenal feeding tubes may be necessary. Studies comparing initiating nasogastric verses nasodudodenal feeding have not found any advantages with nasoduodenal feeding in most patients. Gastric feeding is associated with a significantly quicker initiation of feeds and reaching the target feeding rate without any increase in complications, LOS, or ventilator days $[37,38]$. It is important to point out that patients at high risk for aspiration, or who are intolerant of gastric feedings, be fed via the nasoduodenal route. In this specific population there is an association with reduced episodes of aspiration and pneumonia $[39,40]$.

\section{Enteral formulations}

Multiple enteral formulations exist for the nourishment of the malnourished or at risk patient. Despite much interest over the last decade in various specialty formulations, most studies have failed to identify a benefit. Therefore, it is our practice to utilize polymeric formulations for the majority of our patients. A review of our practices can be found in (Table 3). We will provide the reader with a brief review of the various formulations developed over the past few decades and key studies that have shaped our current practice patterns. There are six main classes of enteral formulations: elemental, semi-elemental, polymeric, diseasespecific, immune modulating/enhancing and anti-inflammatory. Elemental formulations can be thought of as, pre-digested nutrition, and contain individualized amino acids, glucose molecules, and typically low fat preparations. Semi-elemental formulations contain amino acid chains (peptides), simple sugars, and fat composed as medium chain triglycerides (MCT) and long chain triglycerides (LCT). Polymeric formulations are the least processed and contain whole proteins, complex carbohydrates, and long chain fatty acids. Potential benefits of elemental formulations include: better absorption and improved tolerance by patients with malabsorption syndromes or pancreatitis. The major downside of elemental formulations is a near four to eightfold increase in cost. The studies comparing these formulations in patients at risk for malabsorption have failed to show any benefit with elemental formulations despite theoretical benefits [4143]. Even in patients with documented short bowel syndrome the data is conflicting if there is any benefit [44-46]. Similarly, in patients with active Crohn's disease, outside of one study which showed improved remission rates with elemental formulations, no other studies have found a benefit for elemental over nonelemental formulations [47]. One population we do routinely utilize elemental or semi-elemental formulations is in patients with pancreatitis. While once contraindicated, current evidence now supports that patients with acute pancreatitis without ileus be fed via the enteral route as this is associated with reduced infectious complications and improved outcomes [39,40,4850]. The theory behind using an elemental or semi-elemental formulation is the lack of pancreatic enzymes needed to break down polymeric formulations. Data supporting or challenging this practice is currently lacking.

Disease specific or specialty formulations were developed for specific disease states, for example diabetes. These formulations can also be organ specific, for example in pulmonary or renal failure. To give a specific example, in patients with pulmonary failure, it has been theorized that nutritional support with a high fat, low carbohydrate diet can reduce a patient's respiratory quotient. Initial evidence supported this theory and even showed reduced ventilator time in a small sample of patients [51]. In 2003, a larger randomized controlled trial (RCT) attempted to elucidate this and found no benefit utilizing a disease specific formulation for patients with pulmonary failure [52]. This is just 
Table 3 Guidelines for enteral formulation in specific patient populations in patients not tolerating PO.

\begin{tabular}{|c|c|}
\hline General Patients & Standard polymeric formula \\
\hline \multicolumn{2}{|r|}{ Critically III Patients (ICU) } \\
\hline MICU & Standard polymeric formula \\
\hline Perioperative SICU & May consider immune modulating EN \\
\hline Pulmonary failure & Standard energy dense polymeric formula \\
\hline AKI & Standard energy dense polymeric formula \\
\hline AKI with CRRT & $\begin{array}{l}\text { Standard energy dense polymeric formula } \\
+ \text { Protein } 2.5 \mathrm{~g} / \mathrm{kg} / \text { day }\end{array}$ \\
\hline Hepatic failure & Standard polymeric formula (use IBW) \\
\hline Severe sepsis & Standard polymeric formula \\
\hline Burn & $\begin{array}{c}\text { Standard polymeric formula } \\
+ \text { Protein } 2 \mathrm{~g} / \mathrm{kg} / \text { day }\end{array}$ \\
\hline $\mathrm{TBI}$ & $\begin{array}{l}\text { Standard polymeric formula } \\
\text { May consider immune modulating EN }\end{array}$ \\
\hline Obese (BMI>35) & Standard polymeric formula ( $60 \%$ actual BW) \\
\hline Trauma & $\begin{array}{l}\text { Standard polymeric formula } \\
\text { May consider immune modulating EN }\end{array}$ \\
\hline Open abdomen & $\begin{array}{l}\text { Standard polymeric formula } \\
+ \text { Protein } 15 \mathrm{~g} / \text { liter of abdominal losses }\end{array}$ \\
\hline Moderate/severe pancreatitis & Standard elemental, semi-elemental or polymeric formula \\
\hline
\end{tabular}

Intensive care unit, ICU; Medical ICU, MICU; Surgical ICU, SICU; enteral nutrition, EN; acute kidney injury, AKI; continuous renal replacement therapy, CRRT; ideal body weight, IBW; traumatic brain injury, TBI; body mass index, BMI; body weight, BW.

one of example of the failure of disease specific formulations to catch on. Given the lack of robust data supporting disease specific formulations, the most recent ASPEN guidelines recommend against their routine use $[39,40]$. Other formulations include: immune modulating/enhancing and anti-inflammatory. Four specific immunonutrients that have been heavily studied are glutamine, arginine, omega- 3 fatty acids, and omega- 6 fatty acids. There has been much controversy surrounding which populations would benefit the most from these formulations. The 2001 US summit on immune-enhancing enteral therapy's meta-analysis by Daren Heyland of 22 RCTs recommends immune enhancing formulations for the following patient populations: patients undergoing elective gastrointestinal surgery with moderate to severe malnutrition and patients with blunt or penetrating torso trauma with an injury severity score (ISS) $\geq 18$ or an abdominal trauma index $\geq 20.53$.

Glutamine: The theory behind the use of glutamine and arginine is that during periods of stress a patient's natural supply of these amino acids is severely depleted thus making them relatively "essential" amino acids.54 Previously held philosophy recommended the routine use of glutamine in all critically ill patients given this logic; however, recent data has proven that glutamine should not be routinely given to "all critically ill patients" as it may cause harm [53-58]. The METAPLUS and REDOXS landmark studies ended the search for utility of glutamine in critically ill patients $[59,60]$. The REDOXS study was a blinded 2-2 factorial trial of 1223 critically ill patients who were randomized to receive combination enteral and parenteral glutamine, antioxidants, both, or placebo. The authors identified a trend towards increased mortality at 28 days (the primary endpoint) for patients who received glutamine $(32.4 \%$ versus $27.2 \%(p=0.05$, significance defined as $p=0.044$ for this study based on interim analysis)). Furthermore, patients who received glutamine had significantly higher in-hospital and 6-month mortality $(p=0.02)$ [59]. This study ended the controversy of glutamine in critically ill patients and also suggested the routine supplementation of glutamine could be harmful. Of note, the REDOXS study did not specifically evaluate glutamine supplementation in hypoglutaminemic patients. The question remains if there are subsets of patients (i.e., burn and TBI) where glutamine supplementation may be beneficial, as preliminary research in $\mathrm{TBI}$ and burn patients have suggested improved outcomes [61-63].

Arginine: The majority of studies of arginine supplementation in hospital patients has focused on the critically ill, where it is believed arginine can offer the most benefit. One group specifically worth mentioning is supplementation in the postMI population where arginine has been shown to be associated with increased mortality in the Vintage MI study [64]. In the critically ill patient the role of immunomodulation with arginine remains controversial. Five large meta-analyses have evaluated the role of these formulations in the critically ill, all have shown a reduction in infection rates with some showing reduced LOS and ventilator days [65-69]. Patients with sepsis represent a unique consideration for arginine supplementation.

Current ASPEN 2016 guidelines do not recommend the routine use of arginine for critically ill patients with sepsis. In this population the concern with arginine supplementation stems from an increase in nitric oxide (NO) which can exacerbate hypotension; however, studies have failed to definitively show a causal link between arginine supplementation, NO increase, and hypotension/mortality [70]. Further studies are needed to define the appropriate populations who would benefit the 
most from arginine supplementation. For the present, arginine supplementation in sepsis should be utilized at the provider's discretion understanding that any potential benefits have not been fully elucidated; however, supplementation via the enteral route at doses of less than 30 grams/day has not been associated with adverse events.

Omega 3 verses omega 6 fatty acids: Two fatty acids, omega-3 (noninflammatory) and omega-6 (proinflammatory) deserve mention (Figure 1). Western diets are historically high in omega-6 fatty acids, whereas sources of omega- 3 such as flax seed, fish oil (FO), and canola are less common. The role of omega-3 supplementation to curb the inflammatory response in patients with sepsis and acute respiratory distress syndrome (ARDs) has been studied in multiple RCTs and reviewed by Martin et al. [71]. Despite initial studies suggesting a benefit with omega fatty acid supplementation, recent evidence from two RCTs dispute these findings. The OMEGA trial evaluated the role of omega fatty acid supplementation in acute lung injury (ALI) and was stopped early due to lack of efficacy [72]. Another phase II trial evaluated FO (high in omega-3) supplementation in patients with $A L I$ and failed to show a benefit in physiologic or clinical endpoints [73]. The results of these studies are summarized in (Table 4). Given the conflicting data, the most recent ASPEN guidelines do not make a recommendation regarding the use of noninflammatory formulations for patients with ARDS/ALI $[39,40]$.

When to initiate enteral nutrition: To best combat malnutrition, enteral nutrition should be initiated as soon as clinically possible. Historically patients following elective gastrointestinal surgery were kept nothing per os (NPO) until flatus; this practice has since been abandoned as evidence has overwhelmingly supported the safety of early feeding. Furthermore, early feeding as part of enhanced recovery pathways has shown significant reductions in hospital LOS, readmission rates, and rates of complications [74-76]. This includes critically ill patients or those at high nutritional risk. Thus, early (within 48 hours) enteral nutrition is recommended if feasible. This has been highlighted in multiple meta-analyses which have in aggregate shown reduced mortality, reduced infections, and reduced LOS $[39,40,77,78]$ Despite the potential for underfeeding via the enteral route, enteral nutrition is recommended over parental nutrition as it is associated with reduced infectious complications and ICU LOS. While it is ideal to progress to goal feeds as soon as possible, the EDEN study failed to identify any benefit with full feeding over trophic feeding (400 $\mathrm{kcal} /$ day) in patients with ALI [79]. This result is likely due to an increased endogenous generation of glucose during the first week of critical illness. One potential method to improve the rate of underfeeding is through the use of a daily volume based goal (i.e., PEP UP protocol) over a daily caloric based goal. Results for the initial studies utilizing the PEP UP protocol noted patients in the caloric goal group received approximately $58.8 \%$ of their daily caloric needs, whereas patients on the PEP UP protocol received approximately $83.2 \%$ of their daily caloric needs $[80,81]$. We believe the optimal method to combat malnutrition is the early and aggressive feeding of at risk patients via the enteral route. In the face of underfeeding via the enteral route we consider transitioning from calorie to volume based feeding targets.

\section{Parenteral nutrition}

Finally, in patients who do not tolerate enteral feeds and are at risk for malnutrition, parenteral nutrition should be considered, especially if patients are anticipated to require nutritional support for over 7 days. Parenteral nutrition has a few drawbacks. One of the main complications surrounding long term use of PN is the development of liver disease (steatosis and cholestasis). The primary component in PN that appears to drives this is the lipid emulsion [82]. Unfortunately, no emulsion is ideal, and thus multiple formulations exist. Soybean oil has been the formulation of choice since the 1970s; however, recently there has been the development of alternatives, such as: MCT, olive oil (OO), safflower, and FO. While an in-depth review of each agent is outside of the scope of this paper, an important point for the reader to understand is that each of these agents has differing inflammatory profiles [83-85]. For example, soy based emulsions are more pro-inflammatory than olive oil based emulsions, which are more pro-inflammatory than FO based emulsions [82].

Chronic PN should not be discontinued unless in the face of associated bacteremia. For non-malnourished patients, we recommend beginning $\mathrm{PN}$ after seven days in patients who fail enteral nutrition. The key landmark trial supporting this recommendation is the EPaNIC trial which randomized ICU patients with a nutritional risk assessment score $>2$ to early $(2$ days) vs. late (8 days) PN. The late PN group showed a reduced ICU LOS, the primary endpoint, of 3 vs. 4 days $(p=0.02)$. Early $\mathrm{PN}$ was associated with an increased infection rate $(22.8 \%$ vs. 26.2\%, $p=0.008) .86$ Numerous studies have supported this recommendation $[39,40]$. In malnourished patients, $\mathrm{PN}$ should be initiated as soon as possible. Multiple meta- analyses have shown reduced complications and reduced mortality in this population with early PN [86-89].
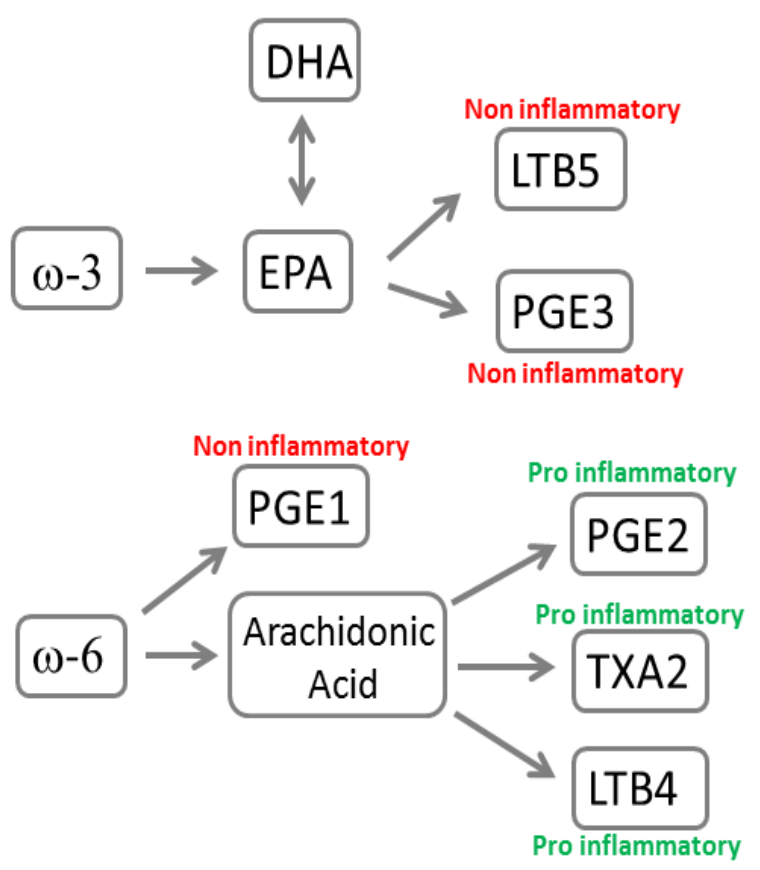

Figure 1 Metabolic pathways of Omega-3 and Omega-6. 
Table 4 Summary of Randomized Controlled Trials comparing noninflammatory enteral regimens.

\begin{tabular}{|c|c|c|c|c|c|}
\hline & Singer et al, 2006 & Gadek et al, 1999 & Pontes-Arruda et al, 2006 & $\begin{array}{c}\text { Rice et al, } 2011 \text { (OMEGA } \\
\text { Trial) }\end{array}$ & Stapleton et al, 2011 \\
\hline Sample Size $(n)$ & $N=100$ & $N=146$ & $N=165$ & $N=272$ & $\mathrm{~N}=90$ \\
\hline Population & $\mathrm{ALI}$ & ARDS & $\begin{array}{c}\text { Sepsis } \\
\text { (Severe or Shock) }\end{array}$ & ALI & ALI \\
\hline \multicolumn{6}{|c|}{ Results } \\
\hline Improved ICU LOS & No & Yes & Yes & No & No \\
\hline Reduced Vent days & Yes & Yes & Yes & No & No \\
\hline Improved mortality & No & No & Yes & No & No \\
\hline Reduced organ failure & N/A & Yes & Yes & No & No \\
\hline
\end{tabular}

Acute lung injury, ALI; acute respiratory distress syndrome, ARDS; intensive care unit, ICU; length of stay, LOS.

\section{Special populations at high risk for malnutrition}

There are a few specific populations at especially high risk for malnutrition: burns, end stage renal disease, liver failure, pancreatitis, critically ill patients requiring vasopressors, and bariatric surgery patients. Specific nutritional considerations are needed in each of these populations to prevent malnutrition.

\section{Burns}

Burn patients are at an exceptionally high rate of nutritional risk due to the hypermetabolic state associated with burns, and the need for frequent conscious sedation requiring interruptions in enteral feeding. We recommend beginning enteral nutrition in these patients within 36 hours if hemodynamically stable. As gastric feeding is associated with frequent interruptions for procedures and conscious sedation for dressing changes, we have developed a protocol utilizing continuous post-pyloric feeding without interruptions. We have found this to be safe with no episodes of procedure related aspiration or complications. 89 Burn patient's energy requirements are frequently under calculated using equations such as the HBE by as much as $100 \%$. A common method of calculating caloric needs for burn patients is to utilize $25 \mathrm{kcal} / \mathrm{kg} /$ day plus a burn factor of $40 \mathrm{kcal} / \%$ of burn surface area/day [90]. Due to higher protein requirements in burn patients, we recommend supplementation on the order of 1.5-2 $\mathrm{g} / \mathrm{kg} /$ day compared with normal requirements of $0.8 \mathrm{~g} / \mathrm{kg} /$ day. Burn patients can remain hypermetabolic for up to 1 year post injury [90]. There are two main drugs which have been utilized to restore metabolic homeostasis in these patients: propranolol and oxandrolone. While the majority of studies have been done in the pediatric population, results have been extrapolated to adult burn patients [91,92]. Our threshold to utilize these medications is in patients with greater than $20 \%$ total body surface area burns.

\section{End Stage Renal Disease and Continuous Renal Replacement Therapy [ESRD and CRRT]}

Critically ill patients requiring CRRT have significantly higher protein needs due to losses that occur across the hemofilter which can be as high as $24 \%$ [93]. Utilizing an escalating protein regimen, Scheinkestel et al. identified that patients requiring CRRT required at least $2 \mathrm{~g} / \mathrm{kg} /$ day of protein in order to maintain a positive nitrogen balance [94]. A positive nitrogen balance was significantly associated with improved in-hospital mortality $(p=0.03)$ and for every $1 \mathrm{~g} /$ day increase in nitrogen balance, they observed a $21 \%$ increase in survival $(p=0.03)$ [94]. When patients transition off CRRT to intermittent hemodialysis one must remember to reduce the protein content.

\section{Liver failure}

Patients with liver failure and ascites are at risk of overfeeding due to calculation errors in weight from excess ascitic fluid. Given this, any equation based calculations should utilize a dry or usual body weight. An additional consideration is to reduce copper and manganese supplementation for patients with hyperbilirubinemia. Historically protein supplementation was restricted, as it was thought to exacerbate hepatic encephalopathy; however, it is now known this is not the case and decreasing protein supplementation can actually worsen encephalopathy. Finally, equations are often inaccurate in this population and therefore use of IC is strongly recommended [95].

\section{Pancreatitis}

Historically patients with pancreatitis were kept NPO until the pancreas "cooled off". This practice has been challenged and the standard of care is to provide enteral nutrition to these patients as multiple RCTs and meta-analyses have shown reduced infections, hospital LOS, multiple organ failure, and mortality with enteral feeding $[96,97]$. The degree of disease severity should guide the route of enteral feeding. Patients with mild disease can be fed by mouth (PO), patients with more severe disease may require nasogastric or nasojejunal feedings. If patients are intolerant to enteral feeding after one week, PN should be started. Another area of controversy has been the role of pro-biotics in pancreatitis. The largest multicenter trial attempting to answer this question demonstrated increased mortality and multiple organ failure in patients treated with pro and pre-biotics vs. pre-biotics alone, but pro-biotic administration was of high doses directly to the duodenum [98]. A meta-analysis comparing pro-biotics with placebo, which included the previously mentioned study, showed reduced infection rate and hospital LOS in the pro-biotic group [99]. At the current time pro-biotics are not recommended for use in patients with pancreatitis, but these findings raise the question whether a different dose, administration protocol, or bacterial type of pro-biotic may be worth investigating.

\section{Hemodynamically unstable patients}

In patients without contraindications to enteral feeds, such as compromised mesenteric vascular supply, bowel obstruction or 
bowel discontinuity, consideration should be given to enteral feeding of patients who require decreasing levels of vasoactive agents for hemodynamic support once the patient is adequately resuscitated. The concern with feeding these patients stems from a reduction in splanchnic blood flow and a $0.3-3.8 \%$ rate of non-occlusive bowel necrosis [100]. Unfortunately, the data for or against feeding through these agents is limited to case reports and case series. One large series reported on 70 patients status post cardiac surgery that early enteral nutrition actually increased cardiac output and splanchnic blood flow in patients on dopamine and norepinephrine [101,102]. One large study evaluated early enteral feeding in 1174 septic patients from multiple institutions requiring vasoactive agents. They compared patients who received enteral nutrition within 48 hours verses those who did not. The group receiving early enteral nutrition had a lower ICU and in-hospital mortality, $22.5 \%$ vs. $28.3 \%$ $(p=0.03)$ and $34 \%$ vs. $44 \%(p<0.001)$, respectively. These results for in-hospital mortality remained significant $(p=0.01)$ for propensity matched patients. Surprisingly, these results were even stronger when taking into account the sickest patients on multiple vasopressors [103]. Another study retrospectively studied outcomes in 259 patients receiving concomitant enteral nutrition and vasopressors [104]. Enteral nutrition was tolerated by $75 \%$ of patients and bowel ischemia was noted in only $0.9 \%$ of patients. On multivariate analysis a norepinephrine equivalent of $\leq 12.5 \mathrm{mcg} / \mathrm{min}$ was associated with enteral nutrition tolerance. Of note, dopamine and vasopressin were least tolerated $(p=0.18$ and 0.0027 , respectively) and conversely patients receiving phenylephrine were more likely to tolerate enteral nutrition $(p=0.0023)$. Due to the lack of truly randomized data to guide management the practitioner should exercise caution around this population.

\section{Bariatric surgery}

As the prevalence of bariatric surgery increases so will the importance of early recognition of specific nutritional deficiencies that may follow. Patients undergoing malabsorptive procedures (i.e., Roux-en-Y gastric bypass) are at significantly higher risk to develop deficiencies than those undergoing restrictive procedures (i.e., gastric banding and gastric sleeves) $[105,106]$. These patients are at specifically high risk for the development of anemia. The two micronutrients most likely to contribute to this disorder include deficiencies in B12 and folate. These patients are also at risk to develop thiamine (B1), iron (Fe), Selenium (Se), Zinc (Zn), and Copper (Cu) trace mineral deficiencies [107]. Secondary to reduced fat digestion, they are particularly prone to develop deficiencies in fat-soluble vitamins ( $A, D, E$, and $K$ ). Unlike water- soluble deficiencies which manifest quickly after surgery, these deficiencies develop later relative to the degree of fat malabsorption [105].

\section{Over and Underfeeding}

In order to prevent and treat malnutrition the optimal delivery of calories is needed. Extremes of calories, over and underfeeding, are both associated with significantly worse clinical outcomes. The risks of overfeeding have been known since the 1990s. Overfeeding is typically associated with the use of $\mathrm{PN}$ as previously mentioned. Chwals defined overfeeding as providing energy in excess of that needed for metabolic homeostasis.108 Excess caloric supplementation has been associated with multiple metabolic derangements. While overfeeding has not been directly associated with increased mortality, it is associated with gastric distension, vomiting, diarrhea, azotemia (from increased exogenous protein), hyperammonemia, hypertonic dehydration, hyperglycemia (less of an issue now-a-days due to improved glucose control), hyperlipidemia, hypertriglyceridemia, hypercapnia, and refeeding syndrome [108-110] Overfeeding can potentially be prevented through the routine use of IC when possible [111]. On the other end of the spectrum, underfeeding can lead to large accumulative negative energy balances which are associated with an increase in infectious complications, poor wound healing, prolonged LOS, and increased mortality. An early, yet pivotal study reported a $76 \%$ mortality associated with critically ill surgical patients who accumulated a 10,000 Kcal negative caloric balance during their hospital stay [112] Techniques to prevent underfeeding include utilizing the PEP uP protocol as previously discussed and using IC to identify appropriate caloric needs. It is imperative that patients at risk for malnutrition or who already have malnutrition receive aggressive and frequent re-evaluation of caloric needs to prevent these dangerous caloric extremes.

\section{Refeeding}

There is one population of severely malnourished patients where the reintroduction of feeds needs to be handled with care. Refeeding syndrome, a true nutritional emergency, was originally identified following World War II [113]. During starvation the body becomes deficient in many electrolytes including phosphate and potassium. However, due to intracellular contraction the serum concentration of these electrolytes remains stable. Upon reintroduction of nutrition, insulin levels increase resulting in intracellular transport of potassium, phosphate, and magnesium causing profound hypophosphatemia (the hallmark of refeeding syndrome) which can have profound physiologic effects. To prevent refeeding syndrome, practitioners must be able to recognize at risk patients. Once recognized, nutritional therapy should proceed slowly and electrolytes checked frequently. Specific populations at risk include: anorexia nervosa, alcoholism, cancer, post-operative, elderly with comorbidities, uncontrolled diabetes mellitus (DM), chronic malnutrition, diuretics, and long term antacid use [114] If refeeding syndrome is diagnosed, feeds should be cut in half and potentially held until repletion of electrolytes is able to be achieved and maintained. If feedings need to be held, they should be restarted slowly after adequate electrolyte replenishment is achieved.

\section{Conclusion}

Despite significant advances in the optimal delivery of appropriate nutrition, large multicenter trials, and exciting cutting edge research, malnutrition continues to go unrecognized, undertreated, and under taught in many hospitals and training programs across the country. While much is known about the optimal delivery of nutrition there are still some significant knowledge gaps. Current research should focus 
on the development of a uniform definition for malnutrition, standardize malnutrition screening protocols, and identify the

\section{References}

1 Butterworth CE (1974) The skeleton in the hospital closet. Nutrition 10: 435-441.

2 Lyder CH, Preston J, Grady JN, Scinto J, Allman R, et al. (2001) Quality of care for hospitalized medicare patients at risk for pressure ulcers. Arch Intern Med 161: 1549-1554.

3 Morris NP (2014) The neglect of nutrition in medical education: a firsthand look. JAMA Intern Med 174: 841-842.

4 Daley BJ, Cherry-Bukowiec J, Van Way CW 3rd, Collier B, Gramlich L, et al. (2016) Current Status of Nutrition Training in Graduate Medical Education From a Survey of Residency Program Directors: A Formal Nutrition Education Course Is Necessary. J Parenter Enteral Nut 40 :95-99.

5 Tappenden KA, Quatrara B, Parkhurst ML, Malone AM, Fanjiang G, et al. (2013) Critical role of nutrition in improving quality of care: an interdisciplinary call to action to address adult hospital malnutrition. J Acad Nutr Diet. 113: 1219-1237.

6 Gallagher-Allred CR, Voss AC, Finn SC, McCamish MA (1996) Malnutrition and clinical outcomes: the case for medical nutrition therapy. J Am Diet Assoc 96: 361-366.

7 Barker LA, Gout BS, Crowe TC (2011) Hospital malnutrition: prevalence, identification and impact on patients and the healthcare system. Int J Environ Res Public Health 8: 514-527.

8 Fry DE, Pine M, Jones BL, Meimban RJ (2010) Patient characteristics and the occurrence of never events. Arch Surg 145: 148-151.

9 Stratton RJ, Green CJ, Elia M (2004) Disease-Related Malnutrition: An Evidence-Based Approach To Treatment edited by Rebecca J Stratton, Ceri I Green, and Marinos Elia, 2003, 824 pages, hardcover. CABI Publishing, Wallingford, United Kingdom. Am J Clin Nutr 79: 1128-1129.

10 Milne AC, Potter J, Vivanti A, Avenell A (2009) Protein and energy supplementation in elderly people at risk from malnutrition. Cochrane Database Syst Rev 18: CD003288.

11 Kubrak C, Jensen L (2007) Malnutrition in acute care patients: a narrative review. Int J Nurs Stud 44: 1036-1054.

12 White JV, Guenter P, Jensen G, Malone A, Schofield M (2012) Academy of $\mathrm{N}$, Dietetics Malnutrition Work G, Force ASPENMT, Directors ASPENBo. Consensus statement of the Academy of Nutrition and Dietetics/American Society for Parenteral and Enteral Nutrition: characteristics recommended for the identification and documentation of adult malnutrition (undernutrition). J Acad Nutr Diet 112: 730-738.

13 Kudsk KA, Tolley EA, DeWitt RC, Janu PG, Blackwell AP, et al. (2003) Preoperative albumin and surgical site identify surgical risk for major postoperative complications. JPEN J Parenter Enteral Nutr 27: 1-9.

14 Wang W, Pan Y, Tang X, Guihua Hao, Yingxin Xie, et al. (2017) Serum prealbumin and its changes over time are associated with mortality in acute kidney injury. Sci Rep 7: 41493.

15 Beck FK, Rosenthal TC (2002) Prealbumin: a marker for nutritional evaluation. Am Fam Physician 65: 1575-1578.

16 Davis CJ, Sowa D, Keim KS, Kinnare K, Peterson S (2012) The use of prealbumin and C-reactive protein for monitoring nutrition support optimal method to determine caloric needs. Additionally, special attention needs to be paid to specific at risk populations for the prevention and treatment of malnutrition.

in adult patients receiving enteral nutrition in an urban medical center. JPEN J Parenter Enteral Nutr 36: 197-204.

17 Lim SH, Lee JS, Chae SH, Ahn BS, Chang DJ, et al. (2005) Prealbumin is not sensitive indicator of nutrition and prognosis in critical ill patients. Yonsei Med J 46: 21-26.

18 Villet S, Chiolero RL, Bollmann MD, Revelly JP, Cayeux RNMC, et al. (2005) Negative impact of hypocaloric feeding and energy balance on clinical outcome in ICU patients. Clin Nutr 24: 502-509.

19 O'Brien KD, Brehm BJ, Seeley RJ, Bean J, Wener MH, et al. (2005) Diet-induced weight loss is associated with decreases in plasma serum amyloid a and C-reactive protein independent of dietary macronutrient composition in obese subjects. J Clin Endocrinol Metab 90: 2244-2249.

20 Manelli JC, Badetti C, Botti G, Golstein MM, Bernini V, et al. (1998) A reference standard for plasma proteins is required for nutritional assessment of adult burn patients. Burns 24: 337-345.

21 Dickerson RN (2016) Nitrogen Balance and Protein Requirements for Critically III Older Patients. Nutrients 8: 226.

22 Leandro-Merhi VA, De Aquino JL (2011) Anthropometric parameters of nutritional assessment as predictive factors of the Mini Nutritional Assessment (MNA) of hospitalized elderly patients. J Nutr Health Aging 15: 181-186.

23 Saeed H. AMJB, Akparibo R, Kolsteren P (2015) Reliability of MidUpper Arm Circumference Measurements Taken by Community Health Nurses. Curr Res Nutr Food Sci 3.

24 Kondrup J, Rasmussen HH, Hamberg O, Stanga Z, Ad Hoc EWG (2003) Nutritional risk screening (NRS 2002): a new method based on an analysis of controlled clinical trials. Clin Nutr 22: 321-336.

25 Johansen N, Kondrup J, Plum LM, Bak L, Nørregaard P, et al. (2004) Effect of nutritional support on clinical outcome in patients at nutritional risk. Clin Nutr 23: 539-550.

26 Heyland DK, Dhaliwal R, Jiang X, Day AG (2011) Identifying critically ill patients who benefit the most from nutrition therapy: the development and initial validation of a novel risk assessment tool. Crit Care 15: R268.

27 Englesbe MJ, Lee JS, He K, Fan L, Schaubel DE, et al. (2012) Analytic morphomics, core muscle size, and surgical outcomes. Ann Surg 256: 255-261.

28 Lee JS, He K, Harbaugh CM, Schaubel DE, Sonnenday CJ, et al. (2011) Frailty, core muscle size, and mortality in patients undergoing open abdominal aortic aneurysm repair. J Vasc Surg 53: 912-91.

29 Miller AL, Min LC, Diehl KM, Cron DC, Chan CL, et al. (2014) Analytic morphomics corresponds to functional status in older patients. J Surg Res 192: 19-26.

30 Stidham RW, Waljee AK, Day NM, Bergmans CL, Zahn KM, et al. (2015) Body fat composition assessment using analytic morphomics predicts infectious complications after bowel resection in Crohn's disease. Inflamm Bowel Dis 21: 1306-1313.

31 Cruz RJ Jr., Dew MA, Myaskovsky L, Goodpaster B, Fox K, et al. (2013) Objective radiologic assessment of body composition in patients with end-stage liver disease: going beyond the BMI. Transplantation 95: 617-622. 
32 Sabel MS, Terjimanian M, Conlon AS, Griffith KA, Morris AM, et al. (2013) Analytic morphometric assessment of patients undergoing colectomy for colon cancer. J Surg Oncol 108: 169-175.

33 Ryan E, Heuberger AL, Broeckling CD, Borresen EC, Tillotson, et al. (2013) Advances in Nutritional Metabolomics. Current Metabolomics 1: 109-120.

34 Freemark M (2015) Metabolomics in nutrition research: biomarkers predicting mortality in children with severe acute malnutrition. Food Nutr Bull 36(1 Suppl): S88-92.

35 Tignanelli CJ, Andrews AG, Sieloff KM, Pleva MR, Reichert HA, et al. (2017) Are Predictive Energy Expenditure Equations in Ventilated Surgery Patients Accurate? J Intensive Care Med (In press).

36 Singer P, Anbar R, Cohen J, Shapiro H, Shalita-Chesner M, et al. (2011) The tight calorie control study (TICACOS): a prospective, randomized, controlled pilot study of nutritional support in critically ill patients. Intensive Care Med 37: 601-609.

37 White H, Sosnowski K, Tran K, Reeves A, Jones M (2009) A randomised controlled comparison of early post-pyloric versus early gastric feeding to meet nutritional targets in ventilated intensive care patients. Crit Care 13: R187.

38 Davies AR, Morrison SS, Bailey MJ, Bellomo R, Cooper DJ, et al. (2012) A multicenter, randomized controlled trial comparing early nasojejunal with nasogastric nutrition in critical illness. Crit Care Med 40: 2342-2348.

39 McClave SA, Taylor BE, Martindale RG, McCarthy M, Roberts P, et al. (2016) Guidelines for the Provision and Assessment of Nutrition Support Therapy in the Adult Critically III Patient: Society of Critical Care Medicine (SCCM) and American Society for Parenteral and Enteral Nutrition (A.S.P.E.N.). JPEN J Parenter Enteral Nutr 40: 159211.

40 Taylor BE, McClave SA, Martindale RG, Malissa MW, Debbie RJ, et al. (2016) Guidelines for the Provision and Assessment of Nutrition Support Therapy in the Adult Critically III Patient: Society of Critical Care Medicine (SCCM) and American Society for Parenteral and Enteral Nutrition (A.S.P.E.N.). Crit Care Med 44: 390-438.

41 Ford EG, Hull SF, Jennings LM, Andrassy RJ (1992) Clinical comparison of tolerance to elemental or polymeric enteral feedings in the postoperative patient. J Am Coll Nutr 11: 11-16.

42 Jones BJ, Lees R, Andrews J, Frost P, Silk DB (1983) Comparison of an elemental and polymeric enteral diet in patients with normal gastrointestinal function. Gut 24: 78-84.

43 Dietscher JE, Foulks CJ, Smith RW (1998) Nutritional response of patients in an intensive care unit to an elemental formula vs a standard enteral formula. J Am Diet Assoc 98: 335-336.

44 McIntyre PB, Fitchew M, Lennard-Jones JE (1986) Patients with a high jejunostomy do not need a special diet. Gastroenterology 91: 25-33.

45 Cosnes J, Evard D, Beaugerie L, Gendre JP, Le Quintrec Y (1992) Improvement in protein absorption with a small-peptide-based diet in patients with high jejunostomy. Nutrition 8: 406-411.

46 Ksiazyk J, Piena M, Kierkus J, Lyszkowska M (2002) Hydrolyzed versus nonhydrolyzed protein diet in short bowel syndrome in children. J Pediatr Gastroenterol Nutr 35: 615-618.

47 Giaffer MH, North G, Holdsworth CD (1990) Controlled trial of polymeric versus elemental diet in treatment of active Crohn's disease. Lancet 335: 816-819.
48 Marik PE, Zaloga GP (2004) Meta-analysis of parenteral nutrition versus enteral nutrition in patients with acute pancreatitis. BMJ 2004 328: 1407.

49 McClave SA, Greene LM, Snider HL, Makk LJ, Cheadle WG, et al. (1997) Comparison of the safety of early enteral vs parenteral nutrition in mild acute pancreatitis. JPEN J Parenter Enteral Nutr 21: 14-20.

50 Windsor AC, Kanwar S, Li AG, Barnes E, Guthrie JA, et al. (1998) Compared with parenteral nutrition, enteral feeding attenuates the acute phase response and improves disease severity in acute pancreatitis. Gut 42: 431-435.

51 al-Saady NM, Blackmore CM, Bennett ED (1989) High fat, low carbohydrate, enteral feeding lowers $\mathrm{PaCO} 2$ and reduces the period of ventilation in artificially ventilated patients. Intensive Care Med 15: 290-295.

52 Mesejo A, Acosta JA, Ortega C, Vila J, Fernández M, et al. (2003) Comparison of a high-protein disease-specific enteral formula with a high-protein enteral formula in hyperglycemic critically ill patients. Clin Nutr 22: 295-305.

53 Proceedings from Summit on Immune-Enhancing Enteral Therapy. (2001) May 25-26, 2000, San Diego, California, USA. JPEN J Parenter Enteral Nutr 25(2 Suppl): S1-63.

54 Worthington ML, Cresci G (2011) Immune-modulating formulas: who wins the meta-analysis race? Nutr Clin Pract 26: 650-655.

55 Wernerman J (2015) How to understand the results of studies of glutamine supplementation. Crit Care 19: 385.

56 van Zanten AR, Hofman Z, Heyland DK (2015) Consequences of the REDOXS and METAPLUS Trials: The End of an Era of Glutamine and Antioxidant Supplementation for Critically III Patients? JPEN J Parenter Enteral Nutr 39: 890-892.

57 Oldani M, Sandini M, Nespoli L, Coppola S, Bernasconi DP, et al. (2015) Glutamine Supplementation in Intensive Care Patients: A Meta-Analysis of Randomized Clinical Trials. Medicine (Baltimore) 94: e1319.

58 Bollhalder L, Pfeil AM, Tomonaga Y, Schwenkglenks M (2013) A systematic literature review and meta-analysis of randomized clinical trials of parenteral glutamine supplementation. Clin Nutr 32: 213-223.

59 Heyland D, Muscedere J, Wischmeyer PE, Cook D, Jones G, et al. (2013) A randomized trial of glutamine and antioxidants in critically ill patients. N Engl J Med. 368: 1489-1497.

60 van Zanten AR, Sztark F, Kaisers UX, Zielmann S4, Felbinger TW, et al. (2014) High-protein enteral nutrition enriched with immunemodulating nutrients vs standard high-protein enteral nutrition and nosocomial infections in the ICU: a randomized clinical trial. JAMA 312: 514-524.

61 Falcao de Arruda IS, de Aguilar-Nascimento JE (2004) Benefits of early enteral nutrition with glutamine and probiotics in brain injury patients. Clin Sci (Lond) 106: 287-292.

62 Garrel D, Patenaude J, Nedelec B, Samson L, Dorais J, et al. (2003) Decreased mortality and infectious morbidity in adult burn patients given enteral glutamine supplements: a prospective, controlled, randomized clinical trial. Crit Care Med 31: 2444-2449.

63 Zhou YP, Jiang ZM, Sun YH, Wang XR, Ma EL, et al. (2003) The effect of supplemental enteral glutamine on plasma levels, gut function, and outcome in severe burns: a randomized, double-blind, controlled clinical trial. JPEN J Parenter Enteral Nutr 27: 241-245. 
64 Schulman SP, Becker LC, Kass DA, Champion HC, Terrin ML, et al. (2006) L-arginine therapy in acute myocardial infarction: the Vascular Interaction With Age in Myocardial Infarction (VINTAGE MI) randomized clinical trial. JAMA 295: 58-64.

65 Beale RJ, Bryg DJ, Bihari DJ (1999) Immunonutrition in the critically ill: a systematic review of clinical outcome. Crit Care Med 27: 2799-2805.

66 Heyland DK, Novak F, Drover JW, Jain M, Su X, et al. (2001) Should immunonutrition become routine in critically ill patients? A systematic review of the evidence. JAMA 286: 944-953.

67 Heys SD, Walker LG, Smith I, Eremin O (1999) Enteral nutritional supplementation with key nutrients in patients with critical illness and cancer: a meta-analysis of randomized controlled clinical trials. Ann Surg 229: 467-477.

68 Montejo JC, Zarazaga A, Lopez-Martinez J, Urrútia G, Roqué M, et al. (2003) Immunonutrition in the intensive care unit. A systematic review and consensus statement. Clin Nutr 22: 221-233.

69 Waitzberg DL, Saito H, Plank LD, Jamieson GG, Jagannath P, et al. (2006) Postsurgical infections are reduced with specialized nutrition support. World J Surg 30: 1592-1604.

70 Rosenthal MD, Carrott PW, Patel J, Kiraly L, Martindale RG (2016) Parenteral or Enteral Arginine Supplementation Safety and Efficacy. J Nutr 146: 2594S-2600S.

71 Martin JM, Stapleton RD (2010) Omega-3 fatty acids in critical illness. Nutr Rev 68: 531-541.

72 Rice TW, Wheeler AP, Thompson BT, deBoisblanc BP, Steingrub $\mathrm{J}$, et al. (2011) Enteral omega-3 fatty acid, gamma-linolenic acid, and antioxidant supplementation in acute lung injury. JAMA 306 1574-1581.

73 Stapleton RD, Martin TR, Weiss NS, Crowley JJ, Gundel SJ, et al. (2011) A phase II randomized placebo-controlled trial of omega- 3 fatty acids for the treatment of acute lung injury. Crit Care Med 39: 1655-1662.

74 Lewis SJ, Egger M, Sylvester PA, Thomas S (2001) Early enteral feeding versus "nil by mouth" after gastrointestinal surgery: systematic review and meta-analysis of controlled trials. BMJ 323: 773-776.

75 Miller TE, Thacker JK, White WD, Mantyh C, Migaly J, et al. (2014) Reduced length of hospital stay in colorectal surgery after implementation of an enhanced recovery protocol. Anesth Analg 118: 1052-1061.

76 Ljungqvist O, Scott M, Fearon KC (2017) Enhanced Recovery After Surgery: A Review. JAMA Surg 152: 292-298.

77 Marik PE, Zaloga GP (2001) Early enteral nutrition in acutely ill patients: a systematic review. Crit Care Med 29: 2264-2270.

78 Doig GS, Heighes PT, Simpson F, Sweetman EA, Davies AR, et al. (2018) Early enteral nutrition, provided within $24 \mathrm{~h}$ of injury or intensive care unit admission, significantly reduces mortality in critically ill patients: a meta-analysis of randomised controlled trials. Intensive Care Med 35: 2018-2027.

79 National Heart, Lung and Blood Institute Acute Respiratory Distress Syndrome Clinical Trials Network, Rice TW, Wheeler AP, Thompson BT, Steingrub J, et al. (2012) Initial trophic vs full enteral feeding in patients with acute lung injury: the EDEN randomized trial. JAMA 307: 795-803.

80 Heyland DK, Cahill NE, Dhaliwal R, Wang M, Alenzi A, et al. (2010) Enhanced protein-energy provision via the enteral route in critically ill patients: a single center feasibility trial of the PEP uP protocol. Crit Care 14: R78.
81 Lee ZY, Barakatun-Nisak MY, Noor Airini I, Heyland DK (2016) Enhanced Protein-Energy Provision via the Enteral Route in Critically III Patients (PEP uP Protocol): A Review of Evidence. Nutr Clin Pract 31: 68-79.

82 Anez-Bustillos L, Dao DT, Baker MA, Fell GL, Puder M, et al. (2016) Intravenous Fat Emulsion Formulations for the Adult and Pediatric Patient: Understanding the Differences. Nutr Clin Pract 31: 596-609.

83 Calder PC, Yaqoob P, Thies F, Wallace FA, Miles EA, et al. (2002) Fatty acids and lymphocyte functions. Br J Nutr 87 Suppl 1: S31-48.

84 Mayer K, Grimm H, Grimminger F, Seeger W (2002) Parenteral nutrition with $\mathrm{n}-3$ lipids in sepsis. Br J Nutr 87 Suppl 1: S69-75.

85 Furukawa K, Yamamori H, Takagi K, Hayashi N, Suzuki R, et al. (2002) Influences of soybean oil emulsion on stress response and cell-mediated immune function in moderately or severely stressed patients. Nutrition 18: 235-240.

86 Casaer MP, Mesotten D, Hermans G, Schetz M, Meyfroidt G, et al. (2011) Early versus late parenteral nutrition in critically ill adults. N Engl J Med 365: 506-517.

87 Heyland DK, MacDonald S, Keefe L, Drover JW (1998) Total parenteral nutrition in the critically ill patient: a meta-analysis. JAMA 280: 2013-2019.

88 Braunschweig CL, Levy P, Sheean PM, Wang X (2001) Enteral compared with parenteral nutrition: a meta-analysis. Am J Clin Nutr 74: 534-542.

89 Krzak A, Taylor S, Cherry-Bukowiec JR, Wang SC (2015) Retrospective Chart Review of Perioperative Enteral Nutrition and Incidence of Aspiration in Adult, Burn Patients. Supplement to J Burn Care and Research 36.

90 Herndon DN, Tompkins RG (2001) Support of the metabolic response to burn injury. Lancet 363: 1895-1902.

91 Herndon DN, Hart DW, Wolf SE, Chinkes DL, Wolfe RR (2001) Reversal of catabolism by beta-blockade after severe burns. N Engl J Med 345: 1223-1229.

92 Hart DW, Wolf SE, Ramzy PI, Chinkes DL, Beauford RB, et al. (2001) Anabolic effects of oxandrolone after severe burn. Ann Surg 233: 556-564.

93 Scheinkestel CD, Adams F, Mahony L, Bailey M, Nyulasi I, et al. (2003) Impact of increasing parenteral protein loads on amino acid levels and balance in critically ill anuric patients on continuous renal replacement therapy. Nutrition 19: 733-740.

94 Scheinkestel CD, Kar L, Marshall K, Bailey M, Davies A, et al. (2003) Prospective randomized trial to assess caloric and protein needs of critically III, anuric, ventilated patients requiring continuous renal replacement therapy. Nutrition 19: 909-916.

95 Kerwin AJ, Nussbaum MS (2011) Adjuvant nutrition management of patients with liver failure, including transplant. Surg Clin North Am 91: 565-578.

96 McClave SA, Chang WK, Dhaliwal R, Heyland DK (2006) Nutrition support in acute pancreatitis: a systematic review of the literature. JPEN J Parenter Enteral Nutr 30: 143-156.

97 Cao Y, Xu Y, Lu T, Gao F, Mo Z, et al. (2008) Meta-analysis of enteral nutrition versus total parenteral nutrition in patients with severe acute pancreatitis. Ann Nutr Metab 53: 268-275.

98 Besselink MG, van Santvoort HC, Buskens E, Boermeester MA, Timmerman $\mathrm{MH}$, et al. (2008) Probiotic prophylaxis in predicted 
severe acute pancreatitis: a randomised, double-blind, placebocontrolled trial. Lancet 371: 651-659.

99 Zhang MM, Cheng JQ, Lu YR, Yi ZH, Yang P, et al. (2010) Use of pre, pro- and synbiotics in patients with acute pancreatitis: a metaanalysis. World J Gastroenterol 16: 3970-3978.

100 McClave SA, Chang WK (2003) Feeding the hypotensive patient: does enteral feeding precipitate or protect against ischemic bowel? Nutr Clin Pract 18: 279-284.

101 Revelly JP, Tappy L, Berger MM, Gersbach P, Cayeux C, et al. (2001) Early metabolic and splanchnic responses to enteral nutrition in postoperative cardiac surgery patients with circulatory compromise. Intensive Care Med 27: 540-547.

102 Berger MM, Revelly JP, Cayeux MC, Chiolero RL (2005) Enteral nutrition in critically ill patients with severe hemodynamic failure after cardiopulmonary bypass. Clin Nutr 24: 124-132.

103 Khalid I, Doshi P, DiGiovine B (2010) Early enteral nutrition and outcomes of critically ill patients treated with vasopressors and mechanical ventilation. Am J Crit Care 19: 261-268.

104 Mancl EE, Muzevich KM (2013) Tolerability and safety of enteral nutrition in critically ill patients receiving intravenous vasopressor therapy. JPEN J Parenter Enteral Nutr 37: 641-651.

105 Shankar P, Boylan M, Sriram K (2010) Micronutrient deficiencies after bariatric surgery. Nutrition 26: 1031-1037.
106 Pournaras DJ, le Roux CW (2009) After bariatric surgery, what vitamins should be measured and what supplements should be given? Clin Endocrinol (Oxf) 71: 322-325.

107 Lakhani SV, Shah HN, Alexander K, Finelli FC, Kirkpatrick JR, et al. (2008) Small intestinal bacterial overgrowth and thiamine deficiency after Roux-en- $Y$ gastric bypass surgery in obese patients. Nutr Res 28: 293-298.

108 Chwals WJ (1994) Overfeeding the critically ill child: fact or fantasy? New Horiz 2: 147-155.

109 Klein CJ, Stanek GS, Wiles CE (1998) 3rd. Overfeeding macronutrients to critically ill adults: metabolic complications. J Am Diet Assoc 98: 795-806.

110 Preiser JC, van Zanten AR, Berger MM, Biolo G, Casaer MP, et al. (2015) Metabolic and nutritional support of critically ill patients: consensus and controversies. Crit Care 19: 35.

111 Fraipont V, Preiser JC (2013) Energy estimation and measurement in critically ill patients. JPEN J Parenter Enteral Nutr 37: 705-713.

112 Bartlett RH, Dechert RE, Mault JR, Ferguson SK, Kaiser AM (1982) Measurement of metabolism in multiple organ failure. Surgery 92 : 771-779.

113 Schnitker MA, Mattman PE, Bliss TL (1951) A clinical study of malnutrition in Japanese prisoners of war. Ann Intern Med 35: 69-96.

114 Mehanna HM, Moledina J, Travis J (2008) Refeeding syndrome: what it is, and how to prevent and treat it. BMJ 336: 1495-1498. 